\title{
Prácticas narrativas no lineales en el webdocumental contemporáneo: bases para una aproximación al fenómeno.
}

Dr. Roberto Arnau Roselló, Universitat Jaume I Castelló

(Grupo de Investigación ITACA), rarnau@uji.es

Resumen: El desarrollo actual de las narrativas no lineales multimedia ha propiciado un aumento exponencial de la producción de contenidos interactivos que tratan de explorar las potencialidades expresivas de las herramientas digitales. De entre la gran variedad de proyectos llevados a cabo, con resultados absolutamente divergentes, es necesario reparar en algunos artefactos comunicativos de compleja definición, más conocidos como webdocumentales en los que confluyen elementos procedentes tanto de las narrativas hipertextuales, por un lado, como del cine documental, por otro. La retórica interactiva de estos nuevos productos pretende relatar historias caracterizadas por una creciente y cada vez más desarrollada relación con el usuario, al que asigna un nuevo lugar en la construcción del sentido. La hibridación de formatos y medios inicia el camino para una reflexión metalingüística y política en esta nueva forma audiovisual, que se abre camino muchas veces al margen de la industria, se produce de modo independiente y se dirige a aquellos espectadores dispuestos a emprender una experiencia narrativa activa.

Abstract: The current development of multimedia nonlinear narratives has led to an exponential increase in content production interactive documentaries that try to explore the expressive potential of digital tools. Among the projects diversity conducted with quite divergent results, it is necessary to notice some definition complex communicative artifacts, better known as webdocumentarys or interactive multimedia documentary, which combines elements from both hypertext narratives, on the one hand such as documentary films, on the other. The rhetoric of these new products interactive storytelling intends characterized by a growing and increasingly developed relationship with the user, which assigns a new place in the construction of meaning. Hybridization of formats and media starts the way for a political metalinguistic consideration in this new audiovisual form, which often finds its way outside the industry, is produced independently and is for those viewers willing to undertake a narrative experience active. 
Biografía: Roberto Arnau Roselló es licenciado en Comunicación Audiovisual por la Universidad de Valencia y doctor en Comunicación por la Universidad Jaume I de Castellón. Ha impartido clases en el Instituto Universitario de Tecnología de la Universidad de Franche Comté (Besançon) donde ha llevado a cabo proyectos tecnológicos, docentes y de investigación. Su actividad se ha desarrollado tanto en el terreno de la investigación, con la publicación de artículos, capítulos de libro y participaciones en congresos, como en el del ejercicio profesional en el medio videográfico y radiofónico, en el que ha realizado múltiples obras audiovisuales y participado en numerosas producciones asumiendo diversas funciones, como realizador, productor, director de fotografía, guionista, ayudante de dirección, etc. Sus líneas de investigación se centran en el análisis de la relación entre cine documental e intervención política, en las que se analiza el modo en que los planteamientos ideológicos y estéticos que hay detrás de cualquier representación interaccionan con los elementos expresivos de la imagen y su puesta en escena. Es miembro del grupo de investigación ITACA UJI y Director del Laboratorio de Ciencias de la Comunicación de la Universitat Jaume I (LABCOM). 


\section{Una olla al fuego}

Incurriríamos en un grave error si tratáramos de minusvalorar el papel desencadenante que está desempeñando la evolución de los dispositivos audiovisuales y los mecanismos tecnológicos en el desarrollo de nuevas subjetividades y modos de expresión a lo largo de la primera década del siglo XXI. Sin abandonar las herramientas retóricas heredadas de los medios precedentes, estas nuevas narrativas visuales han propiciado también nuevos usos, particularizando así sus capacidades expresivas y significantes. A pesar de que esta situación no se ha producido en todos los casos, no debemos obviar el hecho de que desde los inicios del cine el progreso de la tecnología ha permitido la introducción de nuevas técnicas y/o formatos que han llevado aparejados planteamientos estéticos diversos, a la sombra de las posibilidades experimentales asociadas a las evoluciones técnicas concretas de cada momento histórico.

Precisamente, en la actualidad, asistimos al desarrollo y cristalización de un contexto en el que estas transformaciones están generando verdaderas mutaciones en los modos de hacer, de ver, y, en consecuencia, de pensar la imagen. Y aún podríamos decir más, si actualmente hay un producto en el que convergen la mayoría de las cuestiones esenciales de la representación audiovisual digital, éste es, sin duda, el webdocumental. Pero vayamos por partes.

En primer lugar es necesario realizar una precisión terminológica acerca de la naturaleza de nuestro objeto de estudio antes de adentrarnos en un terreno por naturaleza resbaladizo. El análisis del cine documental requiere una posición clara con respecto a su tradicionalmente esencial capacidad de representación de la realidad, que no ofrezca dudas acerca del carácter ideológico de esta identificación del binomio documental/representación de lo real. Como hemos argumentado más profundamente en otro lugar (Gómez, Arnau, 2008: 19), nuestro punto de vista se fundamenta en el uso preferente de la expresión método de trabajo documental, siguiendo a Gauthier (1995), frente al desgastado y obsoleto concepto de cine documental, que presenta profundas contradicciones y ya no puede responder a las derivas del género ni a los interrogantes y desafíos a los que se enfrenta. Por ello, en un intento de superar la rémora de la palabra "documental", tal como expresa Català (2011: 45), hablaremos en adelante de cine de lo real, concepto más abierto que nos permite abarcar un mayor número de obras que implementan una "estrategia enunciativa de carácter documental, apartándose de concepciones arcaicas del género, del corsé que impone el término documental en sí mismo y proponiendo nuevos modelos de significación y estructuración discursiva".

No obstante, no acaban aquí los obstáculos. Sumadas a las dificultades que supone el uso del concepto, las diversas acepciones que se han empleado para referirse al fenómeno del webdocumental han dispersado inicialmente el objeto, situándolo en un terreno por despejar en el que ha sido presa de su propia construcción conceptual. Así, el autor de este trabajo no sabía exactamente a qué atenerse cuando se planteó el estudio de dicha materia, dada la proliferación de expresiones que parecían referirse a lo mismo, de la novedad del formato y de la 
falta de traducción del concepto webdoc en España, donde apenas existen productos similares tal y como se conciben en otros países, sobre todo, Francia, EEUU y Canadá ${ }^{1}$, con una arraigada tradición cinematográfica documental. Frente a un número creciente de acepciones como i-docs, cross-docs, digi-docs, trans-docs, docs multimedia interactivos, docs no-lineales, etc. el autor ha preferido identificar los objetos incluidos en este estudio con el término webdocumental que condensa de modo gráfico una de las potencialidades básicas del nuevo formato, a saber, la confluencia de la narrativa hipertextual propia de Internet (reticularidad, conectividad, interactividad, geolocalización, navegación, multimedialidad, etc.), con aquella específica del cine documental (modos de representación de la realidad, naturalización del discurso). De este modo, la comprensión del fenómeno se realiza desde un punto de vista que abarca todas las manifestaciones generadas por la fértil convergencia entre estos dos ámbitos, de genealogías tan diferentes.

Sin duda, podemos afirmar que los medios interactivos han resituado la experiencia documental del cine de lo real fuera del contexto tradicional de creación-recepción cinematográfica, ya que desplazan a otro terreno cuestiones tan trascendentales como el uso de las herramientas de producción y distribución, el control de la narración por parte del autor, o el papel generativo del nuevo espectador-interactor. La transformación que acarrean está en marcha y nadie sabe cuáles serán sus derivas en el ámbito comunicativo, aunque se intuya la magnitud de sus potenciales transformaciones.

\section{2. ¿De qué hablamos cuando hablamos de webdoc?}

En este sentido, el webdocumental, como manifestación del género multimedia interactivo, se configura como un objeto de compleja definición, que escapa a clasificaciones y taxonomías, al que conviene acercarse desde una perspectiva que contemple el fenómeno como producto del intercambio entre tecnologías hipertextuales y narraciones documentales en un contexto accesible como la web 2.0. Sin embargo, tal y como sostiene el Interactive Documentary Manifesto, siempre que tratemos de internet hay que tener sumo cuidado con lo que allí se considera no ficción, ya que "existe un cierto abuso semántico del término que hace que podamos encontrar bajo esta denominación cierto tipo de productos, de calidad cuestionable, más cercanos en ocasiones a la presentación powerpoint que a la narración documental interactiva" (Almeida, Alvelos, 2011: 125).

A pesar de esta dificultad, encontramos propuestas rigurosas de definición en las investigaciones de algunos autores. Una de ellas es la de Gifreu, para el que los objetos webdoc se podrían identificar con aplicaciones interactivas realizadas con la intención de representar la realidad, documentarla e interactuar con esa representación a través del esquema hipertextual de navegación e interacción (Gifreu: 2011, 238).

\footnotetext{
1 Organismos públicos como el CNC ( Centre National de la Cinematographie) en Francia y la ONF (Office National du Film) en Canadá sustentan la producción de documentales interactivos y son, además, las principales plataformas de distribución del formato.
} 
Su estructura, pues, responde básicamente a un esqueleto hipertextual compuesto por nodos (unidades semánticas que vehiculan un contenido o un concepto), vínculos (elementos que conectan los nodos entre ellos permitiendo la navegación del usuario de uno a otro) y anclas (pequeña parte del nodo a la que se conecta el vínculo), a través del que se manipulan los distintos medios (audio, video, foto, dibujo, etc.).

Este marco funciona como una "red de piezas interconectadas de información textual en la que la mayor carga de significado recae en la elección del modo de vincular los elementos de la información" (Ribas, 2000: 36). De este modo, la estructura del hipertexto rompe con la linealidad y adopta diversas formas en función de la elección, la potenciación del papel del lector, la intervención, la inclusión de hipermedia, su propia complejidad estructural y los elementos variables de la trama, lo que "supone un planteamiento situado en las antípodas de la teoría literaria aristotélica” (Landow, 2005: 271). De alguna manera, el hipertexto hace visible su propia condición discursiva a través de elementos que no están organizados según un orden lógico ni responden a una guía preestablecida de lectura, restringiendo el acto enunciativo a la interacción del usuario, desencadenante de la generación de sentido. Se fuerzan así los límites de la representación documental clásica para construir el sentido en otro lugar, con otros medios.

Por otra parte, este esquema nodal y bifurcado del discurso narrativo permite alterar el orden discursivo, modificarlo hasta tal punto que pueda adoptar una forma contrapuesta a la que inicialmente había plasmado el autor en un guión. Puede invertir la lectura o simplemente interrumpirla, por lo que "se produce una pérdida del control del autor sobre el flujo y el significado de su obra que transforma en cierto modo la autoría en compartida" (Gifreu, 2011: 244) o descentralizada, convirtiendo lo que antes eran dos polos (autor-lector) en un eje autoral que se construye a sí mismo. Este cambio en estatus del espectador supone el tránsito de un espectador pasivo a un interactor activo que gana en presencia, identificación y nivel de intervención en el marco de la obra.

Además, como afirma Gaudenzi (2009: 1) estas aplicaciones online, como mecanismos abiertos y generativos que se relacionan con su entorno a través de los modos de interacción y navegación, "exigen una participación por parte del espectador-usuario que excede el acto hermenéutico con el fin de identificar distintas lógicas de documentación de la realidad y nuevos modelos de subjetividad posibles". De ahí precisamente surgen las enormes diferencias con el documental clásico, que establece un vínculo con la realidad basado en la apariencia de lo real (la imagen) sin reparar en que desde esa perspectiva, su opinión sobre lo real se encuentra encerrada en la ontología que esa misma realidad propone como única posible. Por su parte, el webdocumental, como vanguardia del nuevo cine de lo real, "privilegia la crítica epistemológica de la realidad y su representación desplazando a un segundo término la voluntad mimética o testimonial" (Català, 2011: 46). 
Como nueva articulación de la forma documental, el webdoc es el resultado de la acumulación de varias capas heredadas de los medios anteriores, pero no una "reducción" de esos mismos medios. Sus manifestaciones se sustentan sobre los pilares de la dialéctica permanente entre movimiento (cine) e inmovilidad (foto), que se convierte de ese modo en forma retórica y dispositivo hermenéutico. Al mismo tiempo, se configura como "un acto de conocimiento e implicación del espectador-internauta, cuya interacción actualiza, amplifica o completa una creación previa" (Kerfa, 2011: 692). Dada su inherente multimedialidad, el uso de soportes gráficos como la ilustración o el dibujo que no tienen un vínculo fotográfico con lo real hace que el carácter ficticio de tales representaciones parezca aumentar ${ }^{2}$, pero la huella dejada por la realidad sobre un soporte determinado ya no es la base de este documentalismo expandido, que "persigue el objetivo de moldear imaginativamente algo que fue concebido como real en algún momento" (Català, 2011: 48).

Por todo ello, en línea con lo que propone Gifreu (2010: 50), se afirma como una herramienta con capacidades particulares para articular el sentido de una obra audiovisual, "tratando de estructurar la trama no como una secuencia única de acontecimientos sino como un argumento multiforme abierto a la participación de los usuarios, apoyándose en la no linealidad como estrategia discursiva más cercana a la actual configuración de la cultura en la era digital".

Dichas capacidades implican cambios radicales sobre las de los medios tradicionales y todavía se potencian más si se trata de aplicaciones para dispositivos móviles, en las que el aligeramiento de los equipos o la conectividad generan un tipo de comunicación diferente, táctil, más semántica que sintáctica, geolocalizada, ubicua y asisitida. De todos modos, en muchas ocasiones, el cambio de soporte no implica necesariamente una organización revolucionaria del contenido, ni la apuesta por la web significa experimentación narrativa, las mismas herramientas que pueden hacer de un webdoc una experiencia inmersiva, rigurosa y atractiva pueden convertirlo en una propuesta vacía y anquilosada, a pesar de su "pirotecnia" tecnológica.

\section{Génesis y alcance del género}

Una vez compuesto este sucinto panorama teórico sobre algunas de las propuestas que contribuyen al estudio, definición y análisis del fenómeno webdocumental, en necesario repasar la génesis y progreso de la producción de este formato, prácticamente desconocido en España [existen actualmente dos proyectos de cierto recorrido, como el del Master en Documental Creativo de la UAB, titulado "SEAT: Las sombras del progreso" (2012), o como el del programa En portada de RTVE, "En el reino del plomo" (2013)]. De igual modo que encontramos propuestas y autores interesantes en el horizonte del documental multimedia

\footnotetext{
2 Se pueden consultar diferentes trabajos webdocumentales que responden a este esquema en: http://www.lemonde.fr/webdocumentaires/
} 
interactivo, hemos de destacar el esquematismo inicial del formato, más vinculado a CD Rom interactivos o DVD Rom, tanto fuera de línea como online, que proponen, vistas desde las posibilidades actuales, experiencias muy limitadas desde el punto de vista de la interacción y la navegación ${ }^{3}$.

Es en el año 2002 cuando se nombra por primera vez el término webdoc en la sesión acertadamente titulada "Cinémas de demain"4, en el marco del Festival Internacional de cine documental "Cinéma du Réel", que se celebra en el Centro Georges Pompidou de la capital francesa cada año desde 1978. Todavía se trata de una nueva forma por definir, que apenas ha vislumbrado sus capacidades comunicativas y arrojado ejemplos prácticos de cierto rigor como para construir un corpus visual propio, que requiera la atención de los académicos para generar también un corpus analítico.

Poco a poco, en estos últimos años, con las innovaciones en el campo de la programación informática que inauguran el lenguaje HTML5 y el aumento de la velocidad de conexión de las redes web domésticas, el objeto webdoc empieza a perfilar su carácter actual. A partir de la producción de algunos productos interesantes, en los que el resultado de la combinación y organización de los diferentes elementos textuales consigue aportar un elemento más (quizás el primordial) de significación, su espacio se consolida y se muestra solvente, como la primera producción destacada de la visionaria empresa Upian ${ }^{5}$, en colaboración con el CNC francés: La Cité des mortes: Ciudad Juàrez (Bourgeais, Gonsálvez: 2005), en la que la calidad global del proyecto y la atmósfera única que se genera durante la interacción con la obra dan cuenta de las posibilidades creativas del formato. Poco después la propuesta de Thanatorama, (Guintard, Jesus, Biallais: 2007) ${ }^{7}$ aporta un nuevo elemento fundamental que consiste en la asignación al usuario del papel protagonista de la experiencia. Si de alguna manera el usuario es, por definición, co-propietaro del sentido en el hipertexto, la focalización del relato audiovisual en el plano subjetivo del protagonista de la historia, en este caso la muerte, facilita la identificación del espectador y sirve de base para una experiencia narrativa casi exclusiva hasta este momento del ámbito de los videojuegos, en la que el espectador (ahora también jugador por sus capacidades interactivas y de navegación) se convierte en motor e intérpetre de su propio tránsito diegético.

A partir de estas obras la producción de webdocs experimenta un crecimiento exponencial, oscilando entre dos polos de excelencia encarnados por Upian/CNC/Arte, de un lado, y la ONF, de otro. Destaca la excelencia de las

\footnotetext{
${ }^{3}$ Como ejemplos de estos "proto-webdocs" cabe citar, entre otros: Joan Miró. El color dels somnis. Fundació Joan Miró/Universitat Pompeu fabra, Barcelona, 1998; o Becoming Human. Insitute of Human Origins, Tempe (AZ), 2000.

${ }^{4}$ Cines de mañana (traducción del autor)

${ }^{5} \mathrm{http}: / /$ www.upian.com/

${ }^{6} \mathrm{http}: / /$ www.lacitedesmortes.net/

${ }^{7}$ http://www.thanatorama.com/
} 
propuestas de Gaza/Sderot: La vie malgré tout (Arte: 2008), Voyage au bout du charbon (Bollendorf/Ségretin, Honkytonk Films: 2008), Highrise: Out my window (Cizek, 2010), Les Communes de Paris (Buisson, FÉMIS: 2010) ${ }^{8}$ o la galardonada Prison Valley (Dufresne/Brault, Upian/Arte: 2010).

Es necesario resaltar desde el punto de vista industrial que, a pesar de existir proyectos webdoc de bajo presupuesto, desarrollados por pequeños grupos de trabajo, como La Maraude: à l'écoute de sans-abris (France/Gorisse-Mondoloni, $2010)^{9}$, el formato se construye en base al apoyo institucional de algunas empresas televisivas públicas -nunca privadas- (Arte, BBC, NFB, France 3, etc.) cuyo papel es fundamental en la consecución del formato tal y como se presenta hoy en día. Sólo es necesario comprobar por ejemplo el 28\% del presupuesto de producción de programas que dedicó Arte a la creación documental en el año 201010, o la inclusión de una pestaña específica en su web para este tipo de proyectos transmediáticos. Dicha vinculación se puede detectar también en el hecho de que como género, el webdoc se constituye en heredero del gran reportaje televisivo y otros productos audiovisuales propios de la televisión, como el reportaje o la crónica, sin embargo, sus capacidades significantes le han permitido exceder el ámbito estrictamente televisivo y penetrar en un terreno más próximo al del cine ensayo (en algunos casos), más propenso a las digresiones, a la apertura del sentido y a la subjetividad del autor. A pesar de las múltiples variables exploratorias que permite la programación web sus esquemas estructurales son en cierto modo básicos, revestidos de un cierto minimalismo formal como parte de la estrategia discursiva a través de la que se trata de incitar al internauta a explorar las diferentes vías posibles de profundización, complemento o análisis de la información. En este momento, el webdocumental se perfila como una herramienta por naturaleza hermenéutica, dialéctica, abierta en lugar de cerrada, que parte de la interacción física del usuario para desplegar su discurso, arborescente en lugar de lineal, dialógica en lugar de omnisciente, nueva y de proyección futura, sólo habrá que estar atento a la emergencia de propuestas interesantes que nos ofrece la red.

\section{Referencias Bibliográficas:}

ALMEIDA, A., ALVELOS, H. (2010): “An Interactive Documentary Manifesto". En: Interactive Storytelling, ICIDS, Edinburgh: LNCS, vol. 6432, Springer, Berlin / Heidelberg, pp. 123-128.

CATALÀ, J. M. (2011): "Reflujos de lo visible. La expansión post-fotográfica del documental”. En: Adcomunica Revista de estrategias de Comunicación, no2, Castellón de la Plana: Asociación para el desarrollo de la comunicación Adcomunica, Universidad Complutense de Madrid, Universitat Jaume I, 43-62.

8http://www.lescommunesdeparis.fr/

${ }^{9}$ http://www.dna.fr/maraude/

10http://www.arte.fr 
GAUDENZI, S. (2009): Digital interactive documentary: from representing reality to cocreating reality, London: University of London, Center for Cultural Studies.

GAUTHIER, G. (1995): Le documentaire: un autre cinema, Paris: Nathan.

GIFREU, A. (2010): El documental multimedia interactiu. Una proposta de model

d'análisi. Barcelona: Universitat Pompeu Fabra.

GIFREU, A. (2011): "El Nuevo discurso de la no ficción interactiva y su aplicación para dispositivos móviles. El caso del documental multimedia interactivo". En:

Revista Geminis, Año 2, no 1, Junio 2011, http://www.revistageminis.ufscar.br.

[Recuperado el 10 de Enero de 2013]

GÓMEZ TARÍN, J.; ARNAU ROSELLÓ, R. (2008): “Aproximació historiográfica”. En

GIL, L.; MARZAL, J. (2008): Eines per la producció del video documental, Benicarló, Onada Edicions.

KERFA, S. (2011): “El documental interactivo o la realidad arborescente como

forma de investigar el mundo contemporáneo. El caso de la cadena Arte: una televisión comprometida con la red", En BORT, I., GARCIA, S., MARTÍN, M. (2011): Actas del IV Congreso Internacional sobre Análisis Fílmico, Nuevas tendencias e hibridaciones de los discursos audiovisuales en la cultura digital contemporánea, Castellón: Universidad Jaume I.

LANDOW, G. (2005): Hipertexto 3.0: teoría crítica y nuevos medios en la era de la globalización. Barcelona: Paidós.

RIBAS, J. I. (2000): Caracterització dels interactius multimedia de difusió cultural. Aproximació a un tractament específic, els "assaigos Interactius”, Barcelona, Universitat Pompeu Fabra, Facultat de Comunicació.

*El presente estudio ha sido financiado con la ayuda del Proyecto de Investigación de la convocatoria Universitat Jaume I-Bancaja, con el título "Análisis de los flujos de transferencia de conocimiento entre los sistemas educativos superiores y la industria del videojuego", código 11I301.01/1, para el periodo 2012-14, bajo la dirección del Dr. Javier Marzal Felici. 